\title{
Effect of mating delay on the ovary of Melipona quadrifasciata anthidioides (Hymenoptera: Apidae) queens
}

\author{
Edmilson Amaral de Souza ${ }^{a}$, Clóvis Andrade Neves ${ }^{\text {a }}$, Lucio Antonio de Oliveira Campos ${ }^{\text {a }}$, \\ José Cola Zanuncio ${ }^{\mathrm{b}}$, José Eduardo Serrão ${ }^{\mathrm{a}, *}$ \\ ${ }^{a}$ Departamento de Biologia Geral, Universidade Federal de Viçosa, Av. P.H. Rolfs s/n, CEP 36570-000 Viçosa, MG, Brazil \\ ${ }^{\mathrm{b}}$ Departamento de Biologia Animal, Universidade Federal de Viçosa, Brazil \\ Received 26 June 2006; received in revised form 18 August 2006; accepted 20 August 2006
}

\begin{abstract}
The effect of mating delay on the ovary structure of virgin queens of Melipona quadrifasciata anthidioides (Hymenoptera: Apidae) was investigated. Virgin queens 15, 20, 25 and 30 days old were dissected to analyze their degree of ovary degeneration. To verify whether the degeneration would cause permanent sterility, virgin queens of the same ages (15, 20, 25 and 30 days) were mated and accompanied for at least 14 days to verify whether there was physogastry and then dissected. The ovaries were analyzed by histology, histochemical tests and TUNEL to verify programmed cell death. The results showed that mating delay interrupted oogenesis preventing vitellogenesis. Mating delay results in ovary degeneration which increased with queen age. However, even when there was ovariole degeneration, 25-day-old virgin queens after mating presented normal ovariole activation.
\end{abstract}

(C) 2006 Published by Elsevier Ltd.

Keywords: Ovary degeneration; Virgin queen; Mating; Oosorption

\section{Introduction}

Bees have meroistic polytrophic ovarioles (Snodgrass, 1935; Chapman, 1998; Büning, 1994). Thus oogenesis in bees, as in other insects with meroistic ovarioles, can be divided into several stages. The first stage is characterized by oogonia B or cystoblast proliferation until the typical number of cells is reached for the cysts of each species. Later, the oocyte is differentiated from the other cystocytes. In the next stage the follicles show an organization in oocytic and nurse chambers lined by follicle cells. The ovariole grows and polyploidization of the nurse cells takes place. The oocyte grows exclusively due to material transferred by the nurse cells at this stage (Ries, 1932; Büning, 1994; Cruz-Landim, 2004).

The start of yolk uptake in the oocyte characterizes vitellogenesis. This yolk uptake occurs initially at the periphery in the form of small basophillic granules. The haemolymph material can be transferred to the oocyte through intercellular spaces or by the transcellular pathway in the follicles cells (Fill, 1978; Fleig, 1995).

\footnotetext{
* Corresponding author. Tel.: +55 31 38991301; fax: +55 3138992549 .

E-mail address: jeserrao@ufv.br (J.E. Serrão).
}

Yolk uptake advances and yolk granules of various sizes begin to occupy practically all the ooplasm. The vitellinic membrane is also produced in this stage but it does not prevent yolk deposit. The last stage of oocyte production is characterized by the disappearance of the nurse chamber and chorion synthesis (Ries, 1932; Chapman, 1998; Cruz-Landim, 2004).

Mating is the main stimulus for the oogenesis process and is responsible for the start of egg maturation in insects (Davis, 1964; Watson, 1964; Engelmann, 1970; Wheeler, 1996).

Mating can trigger the activation of the ovary in insects either chemically, through substances produced together with the semen (Chen et al., 1988; Coleman et al., 1995; Wolfner, 1997), or by stimuli on the nerve endings of the genital tract (Bell and Bohm, 1975; Melo et al., 2001), where this stimulus could induce juvenile hormone production by the corpora allata and consequently the start of vitellogenesis or both factors can be involved (Wheeler, 1996).

Ovary activation is an unknown process, although hormonal influence under normal conditions is unquestionable, because the haemolymph titers of juvenile hormone and ecdysteroids affect the ovary (Bownes, 1989; Hartfelder et al., 2002).

Mating accelerates the oogenesis process in bees so its absence may cause several modifications in the reproductive 
tract of the insects including the oocyte (Bell and Bohm, 1975), nurse and follicle cells reabsorption (Patricio and CruzLandim, 2002; Martins and Serrão, 2004).

Twelve to 16-day-old virgin queens of Apis mellifera presented destructured ovarioles (Patricio and Cruz-Landim, 2002). However, 30-day-old non-mated virgin queens could be fertilized and produced eggs normally (Chaud-Netto and Stort, 1980).

According to Martins and Serrão (2004), mating delay affects the ovaries of Melipona quadrifasciata anthidioides queens, but it is not known whether this degeneration results in permanent sterility. Thus the objective of this study was to accompany the ovarian strucuture in M. q. anthidioides virgin queens and verify whether this feature prevented oogenesis in them after mating.

\section{Materials and methods}

M. q. anthidioides were obtained from colonies in the Central Apiary at the Federal University of Viçosa, Minas Gerais, Brazil. The queens were obtained from the brood combs removed from the colonies, maintained at $29 \pm 1{ }^{\circ} \mathrm{C}$ and observed daily to detect newly emerged queens. The newly emerged queens were placed separately in Petri dishes $(12 \mathrm{~cm})$ containing 10 workers and received pollen and honey ad lib. in the first 5 days of adult life. After 5 days, the queens were transferred to glass-covered wood boxes
$(15 \mathrm{~cm} \times 7.5 \mathrm{~cm} \times 15 \mathrm{~cm})$ and were fed on pollen and honey and receive cerume. Workers were added in the boxes daily.

The males were obtained by separating the newly emerged and rearing them until they reached reproductive age (about 9 days old; Camargo, 1984) or they were collected in the field.

A total of 15 queens was studied to accompany ovary degeneration, three queens per age. Newly emerged queens were used as control and 15, 20, 25 and 30-day-old virgin queens were dissected to study their ovaries.

Eight queens were studied to verify whether the absence of mating would influence their fertility, two virgin queens from each age group $(15,20,25$ and 30 days). They were removed from the boxes and placed in the presence of males on Petri dishes $(12 \mathrm{~cm})$ for mating. After mating, the queens were replaced in the wood boxes and observed for a period of at least 14 days to ascertain occurrence of physogastry and the ovaries were then dissected.

The reproductive tracts were dissected in saline solution for insects and transferred to Zamboni fixative solution (Stefanini et al., 1967), and later dehydrated in a graded ethanol series, embedded in historesin JB4, sectioned at $5 \mu \mathrm{m}$ thickness and stained with hematoxylin and eosine.

Some sections were submitted to the PAS histochemical tests to evidence polysaccharides and neutral glyco-conjugates and to the mercury-bromophenol test to evidence proteins (Pearse, 1985).
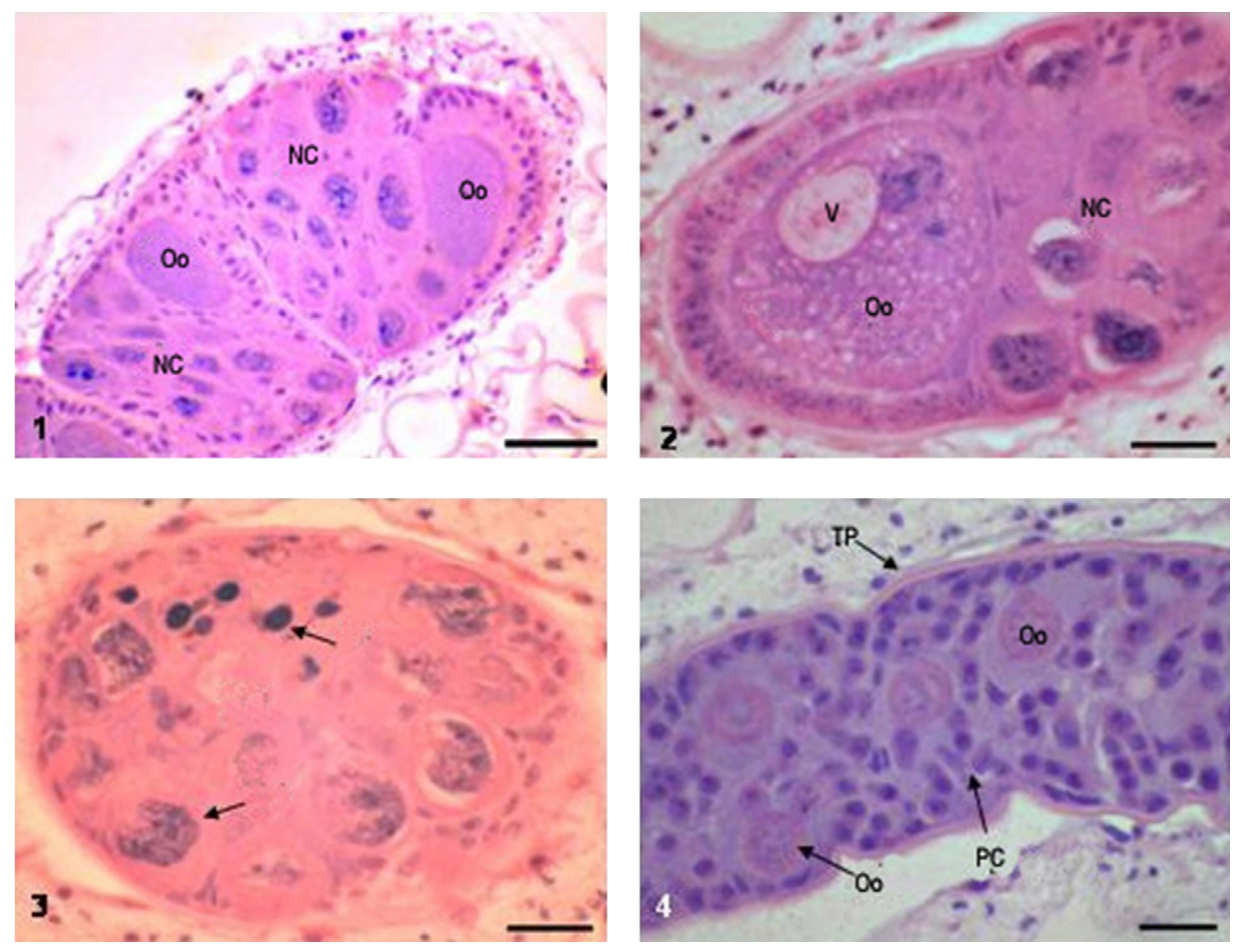

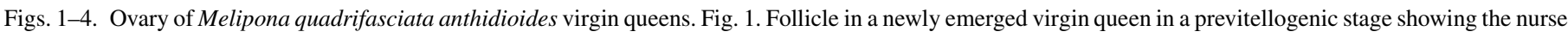

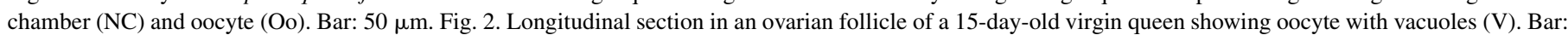

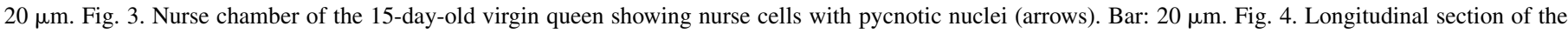
germarium in a 15-day-old virgin queen showing oocytes in differentiation (Oo). PC, prefollicular cells; TP, tunica propria. Bar: $50 \mu \mathrm{m}$. 
To verify cell death occurrence in the reproductive tract of the virgin queens at the ages reported previously, ovaries, after dissection were transferred to Zamboni fixative solution, dehydrated in a graded ethanol-xylene series, embedded in paraffin, sectioned at $7 \mu \mathrm{m}$ thickness and submitted to the in situ cell death detection kit (TUNEL Technology, Roche, cat. n. 18684817) following the manufacturer's instructions. After paraffin has been removed, sections were submitted to permeabilisation solution $(0.1 \%$ Triton $\mathrm{X}-100,0.1 \%$ sodium citrate), rinsed twice with sodium phosphate buffer (PBS), incubated in the TUNEL reaction mixture for $60 \mathrm{~min}$ at $37^{\circ} \mathrm{C}$, rinsed three times with $\mathrm{PBS}$, incubated in an anti-fluorescein antibody from sheep conjugated with horseradish peroxidase for $30 \mathrm{~min}$ at $37{ }^{\circ} \mathrm{C}$, washed twice with PBS and incubated in the presence of DAB and hydrogen peroxide. The negative control was performed by omitting the enzymatic solution associated to the marker solution in the TUNEL reaction mixture and positive control was performed by submitting the material before the procedure to DNase in Tris- $\mathrm{HCl}$ buffer for $10 \mathrm{~min}$ at $15-20^{\circ} \mathrm{C}$.

\section{Results}

The ovarioles of newly emerged queens were long and with germarium and vitelarium regions, but the follicles were at the pre-vitellogenic stage (Fig. 1). The cells in the germarium and in the vitelarium did not show signs of death.
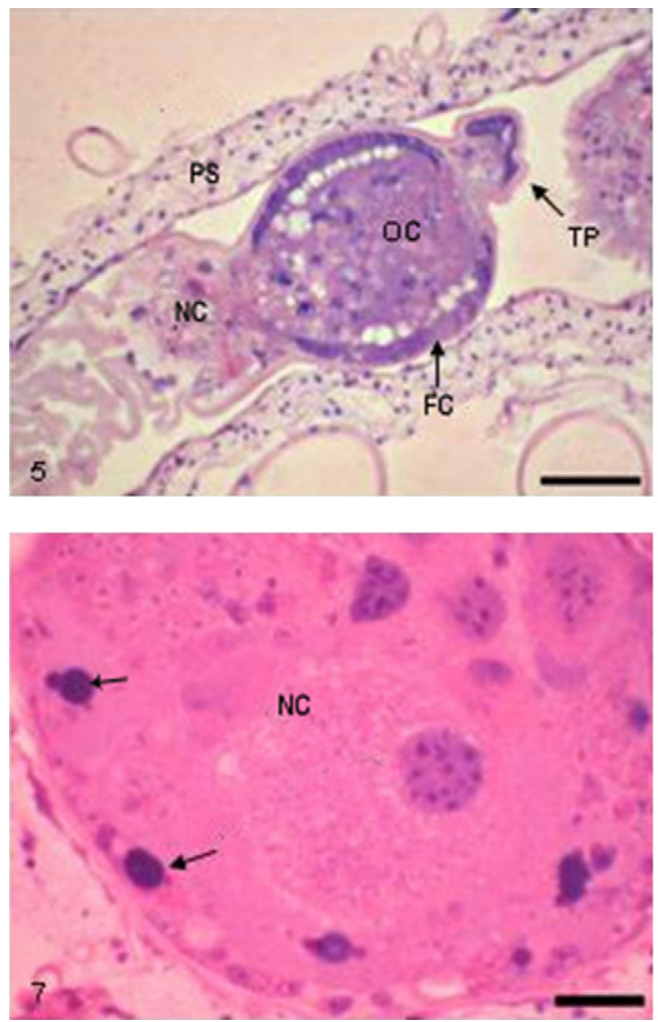

Morphological alterations were observed in 15-day-old virgin queens. The ovarioles presented alterations in the vitelarium region, with the oocytes presenting large vacuoles (Fig. 2). Nurse cells presented atypical morphology with large vacuoles in the cytoplasm and pycnotic nuclei (Fig. 3). Even with signs of degeneration, the general structure of the ovariole remained intact, with flattened follicle cells surrounding the nurse chamber and cubic or columnar follicle cells surrounding the oocyte chamber. The germarium has not signs of degeneration (Fig. 4).

Twenty-day-old virgin queens presented an advanced stage of degeneration in the nurse cells in the vitelarium and the tunica propria surrounding the ovariole was thick in this region (Fig. 5). Unlike the 15-day-old queens, the disorganization in the germarium apparently started in its periphery (Fig. 6). This disorganization was characterized by the presence of an amorphous material on the germarium periphery. After 20 days of age, the follicle cells in the nurse chamber were not easily identified.

In 25-day-old virgin queens, ovary degeneration was at a more advanced stage. Several nutritive cells showed pycnotic nuclei (Fig. 7) and regions with amorphous material in the periphery were found in the germarium associated to undifferentiated cells (Fig. 8).

The vitelarium was not identified in 30-day-old virgin queens. At this stage, the ovarioles consisted of germarium region covered by a thick tunica propria, peritoneal sheath and tracheal branches (Fig. 9 ).
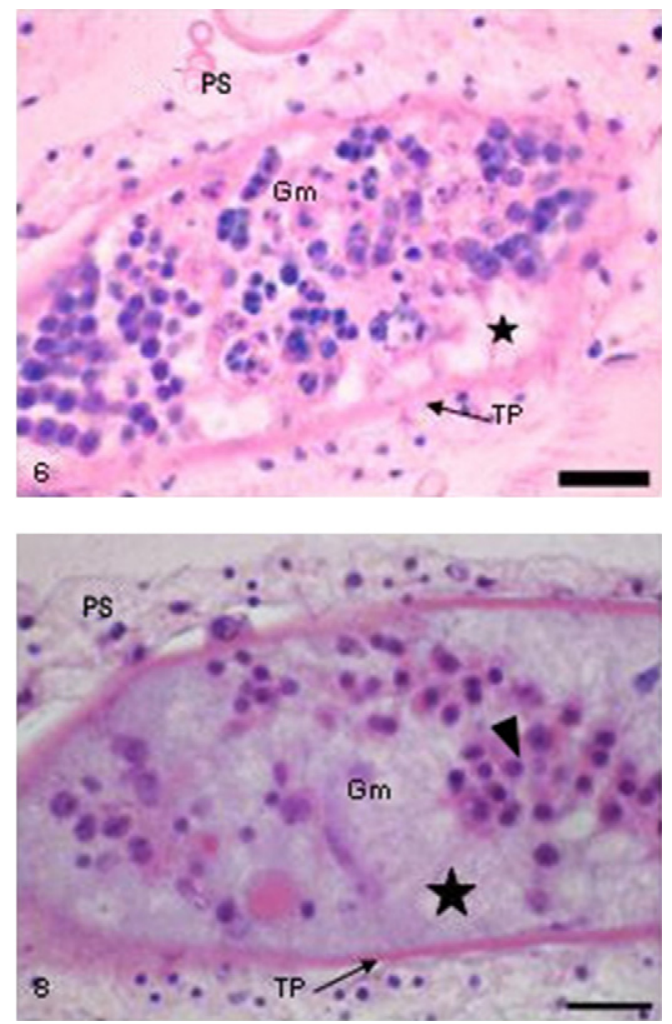

Figs. 5-8. Ovary of Melipona quadrifasciata anthidioides virgin queens. Fig. 5. Follicles in advanced stage of degeneration in 20-day-old virgin queen. Bar: $20 \mu \mathrm{m}$. Fig. 6. Germarium $(\mathrm{Gm})$ with periphery in initial stage of degeneration (star) in 20-day-old virgin queen. Bar: $20 \mu \mathrm{m}$. Fig. 7. Nurse chamber (NC) with nurse cells presenting pycnotic nucleus (arrows) in 25-day-old virgin queen. Bar: $20 \mu \mathrm{m}$. Fig. 8. Germarium $(\mathrm{Gm})$ with peripheral region with amorphous material (star) in 25day-old queens together with undifferentiated cells. Bar: $20 \mu \mathrm{m}$. Arrowhead, pycnotic nucleus, OC, oocytic chamber; FC, follicular cells; PS, peritoneal sheath, TP, tunica propria. 

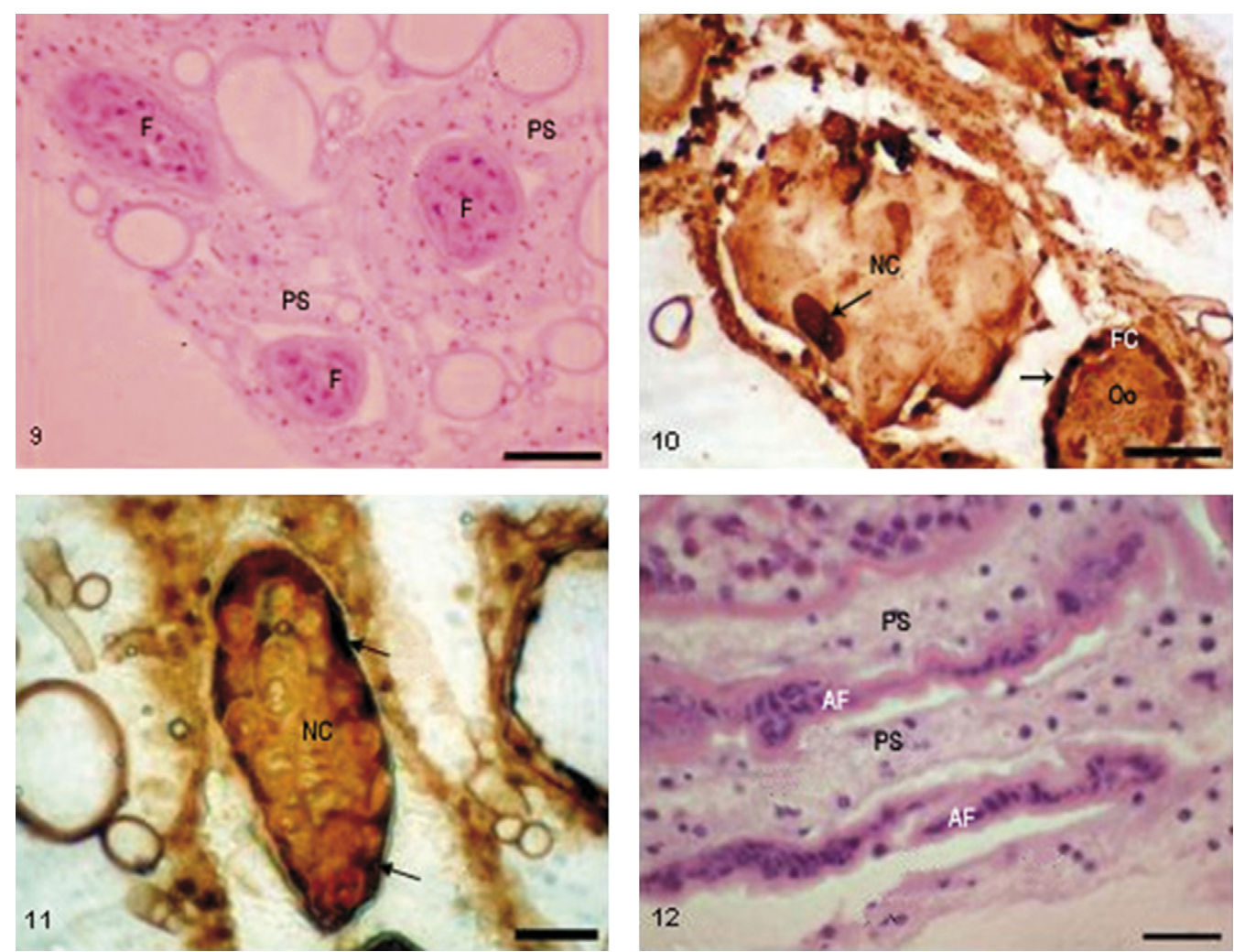

Figs. 9-12. Ovary of Melipona quadrifasciata anthidioides virgin queens. Fig. 9. Follicles (F) in 30-day-old virgin queen involved for thick peritoneal sheath (PS). Bar: $50 \mu \mathrm{m}$. Figs. 10 and 11. Ovaries in virgin queen showing nurse cells (NC) and follicular cells (FC) with positives nucleus (arrows) to TUNEL test. Oo, oocyte. Bar: 50 and $20 \mu \mathrm{m}$. Fig. 12. Atresic follicles (AF) in 30-day-old virgin queen with few follicular cells and thick peritoneal sheath (PS). Bar: $20 \mu \mathrm{m}$.

In all the virgin queens analyzed, follicle and nurse cells were positive for the TUNEL test (Figs. 10 and 11) and the vitellogenesis process was not verified.

Atresic follicles were detected in queens after 15 days of age and were characterized by a great number of follicle cells covered by a thick tunica propria. There were fewer follicle cells in 30-day-old queens (Fig. 12).

Analyses of the sections submitted to the mercury-bromophenol test showed positive reactions in the tunica propria (Fig. 13) and muscle cells in the peritoneal sheath (Fig. 14). The tunica propria presented variable thickness depending on the stage of the ovary, and was thick in regions where cell reabsorption was occurring but thin in unaffected regions.

The PAS test was positive in the germarium, vitellarium and tunica propria of virgin queen up to 25 days of age (Figs. 15 and 16).

Fifteen, 20 and 25-day-old virgin queens were physogastric after mating. The nurse cells in these mated queens were large with well developed nucleus and descondensed chromatin (Fig. 17). Follicle cells showed typical morphology, and were flattened in the nurse chamber and cubic or columnar in the oocyte chamber (Fig. 18). Yolk granules were found in the oocytes by the mercury-bromophenol test, that indicated that the vitellogenesis process was taking place (Fig. 19). Small yolk granules were located in the oocyte periphery and larger ones in the oocyte central region.

The tunica propria, germarium, nurse cells and oocytes were PAS-positive in mated queens (Figs. 17, 20 and Figs. 21, 22).
Thirty-day-old virgin queens were succesfull mated, but there was no ovary activation and they died a few days after mating.

\section{Discussion}

Oocyte growth in insects depends on the nutritional, hormonal, mating and age factors (Telfer, 1965; Engelmann, 1970; Bell and Bohm, 1975; Wheeler, 1996), but oviposition requires ovary development and mating (Hatakoshi, 1992).

Our results showed that mating delay in $M$. q. authidioides queens caused disorganization in the ovariole. Virgin queens more than 15 days old presented cells with signs of death, characterized by the vacuolized cytoplasm and pycnotic nuclei, whereas in younger virgin queen these characteristics were not present (Martins and Serrão, 2004). So in this older virgin queens the vitellogenesis was prevented.

The age togeher the mating delay further enhance the ovariole degeneration in M. q. authidioides likely reported in $A$. mellifera queens (Patricio and Cruz-Landim, 2002).

In addition to death of nurse cells, mating delay and aging caused oosorption. Fiften day-old virgin queens presented signs of oosorption (Martins and Serrão, 2004) and oosorption was more frequent as they aged and in 30-day-old virgin queens oocytes were lacking. Oosorption is a reproductive strategy by which the oocyte degenerate to conserve energy in response to behavioral, ecological or physiological factors by interrupting yolk uptake (Bell and Bohm, 1975). Nutritional deficiency is 

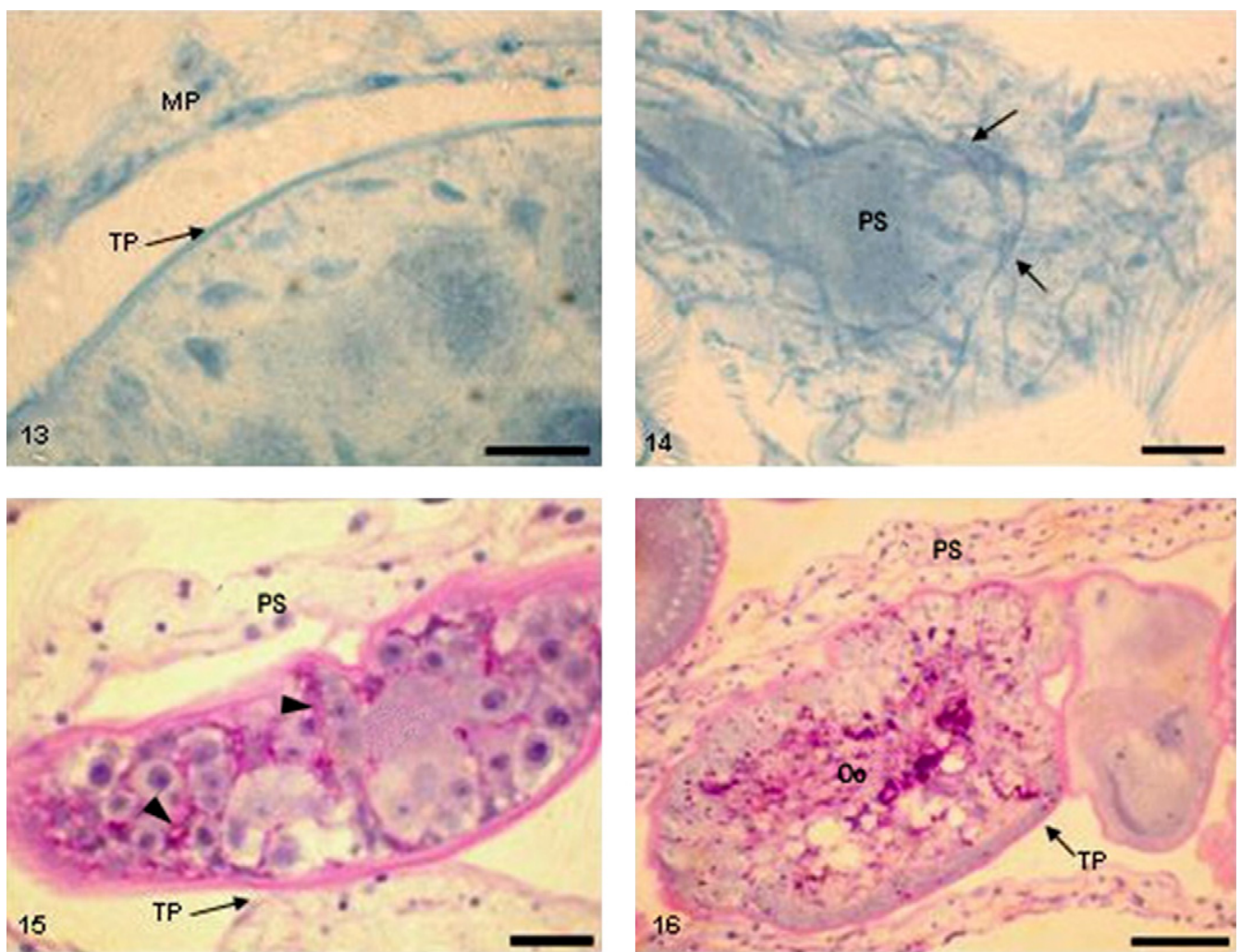

Figs. 13-16. Ovary of Melipona quadrifasciata anthidioides virgin queens. Fig. 13. Tunica propria (TP) detected by mercury-bromophenol. Bar: $10 \mu m$. Fig. 14. Peritoneal sheath (PS) with a several muscular fibers (arrows) detected by mercury-bromofenol. Bar: $20 \mu \mathrm{m}$. Fig. 15. Undifferentiated cells PAS-positive (arrowheads) in germarium of the 25-day-old virgin queen. Bar: $50 \mu \mathrm{m}$. Fig. 16. PAS-positive region in oocyte (Oo) in reabsorption in 25 -day-old virgin queen. Bar: $50 \mu \mathrm{m}$. PS, peritoneal sheath; TP, tunica propria.
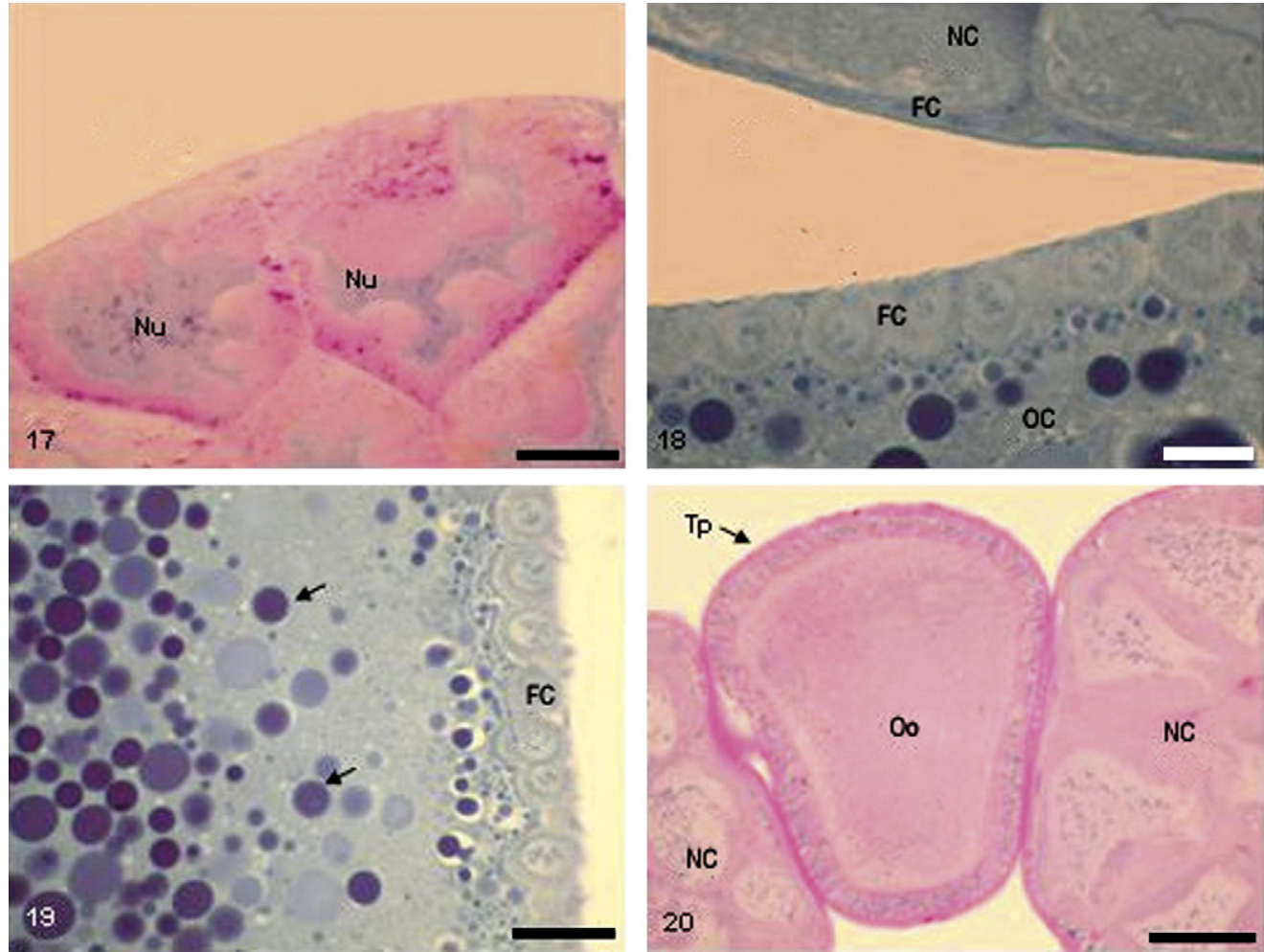

Figs. 17-20. Ovary of Melipona quadrifasciata anthidioides mated queens. Fig. 17. Nurse cells positives to the PAS test in a queen mated at 25 days old. Nu, nucleus. Bar: $50 \mu \mathrm{m}$. Fig. 18. Cubic follicular cells (FC) of the oocytic chamber (OC) and flattened ones in nurse chamber (NC). Bar: $20 \mu \mathrm{m}$. Fig. 19. Yolk granules (arrows) detected by mercury-bromofenol in oocytic chamber of a queen mated at 25 days old. Note follicle cells (FC) with features of high synthetic activity. Bar: $50 \mu \mathrm{m}$. Fig. 20. Oocyte (Oo) and nurse chamber (NC) with PAS-positive tunica propria (TP) in queen mated 25 days old. Bar: $50 \mu \mathrm{m}$. 

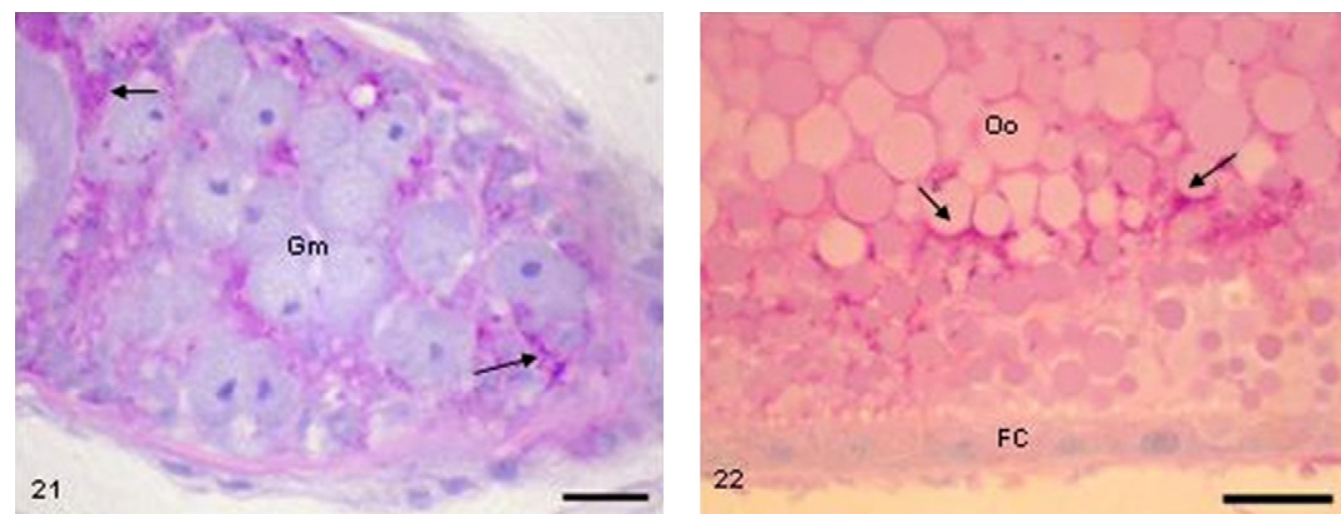

Figs. 21-22. Ovary of Melipona quadrifasciata anthidioides mated queens. Fig. 21. Germarium (Gm) of queen mated at 25 days old with PAS-positive granules (arrows). Bar: $50 \mu \mathrm{m}$. Fig. 22. PAS-positive granules (arrows) in oocyte (Oo) of queen mated at 25 days old. FC, follicular cells. Bar: $50 \mu \mathrm{m}$.

the mean cause of oosorption, but other factors such as seasons, parasitism, age, social pressure (reproductive dominance by an individual) and absence of mating are closely associated (Bell and Bohm, 1975). Oosorption may occur at any stage of oogenesis and during follicle atresia the follicle epithelium remains intact (Huebner, 1981). Our results showed that regions with advanced follicle atresia were characterized by a large number of follicle cells covered by a thick tunic propria and that the number of follicle cells apparently decreased in older queens.

Oosorption in $M$. q. anthidioides virgin queens occurred before the vitellogenesis process started. This corroborates the importance of mating as stimulus for the start of oocyte maturation in this stingless bee such as found in other insects (Davis, 1964; Watson, 1964; Engelmann, 1970; Wheeler, 1996).

The tunica propria is an elastic extracellular matrix that supports the ovarioles maintaining their shape and acting as a selective physical barrier during the previtellogenesis period (Chapman, 1998; Büning, 1994). Its aspect and thickness may vary depending on the ovary developmental stage (Chapman, 1998). In old A. mellifera queens, regions of the terminal filament with cell disintegration had thick tunica propria (CruzLandim, 2004) likely herein presented with degenerating regions have the tunica propria thick while in apparently normal ovary regions it was thin. Since vitellogenesis is inhibited in virgin queens, the tunica propria thickness may increase due to its retraction as result of follicle reabsorption and consequently reduced ovariole volume. A basement membrane thickening was found in the transition from larva to pupa in the $M$. $q$. authidioides midgut, where the larval midgut epithelium was lost and later substituted by another derived from regenerative cells (Neves et al., 2003). Once the larval epithelium was caste of, the midgut volume decreased and consequently there was a retraction in the basement membrane forming infoldings (Neves et al., 2003). The thickening of the tunica propria in the M. q. authidioides ovaries might occur similarly to the retraction of the midgut basement membrane forming infoldings in the ovariole wall.

Although we found that ovariole degeneration in M. $q$. authidioides queens progressed according to age, this degeneration did not cause permanent sterility in queens until they were 25 days old, because vitellogenesis that did not occur in virgin queens, occurred normally after their mating. In $A$. mellifera, the ovariole degeneration began in 12 day-old virgin queens (Patricio and Cruz-Landim, 2002), but virgin queens up to 30 days old could be fertilized and make oviposition (ChaudNetto and Stort, 1980).

The yolk consists predominantly of proteins, but lipids and glycogen may be present, located among the protein granules (Cruz-Landim and Cruz-Höfling, 1971). Glycogen can be found both in the ooplasm and inside the granules. This statement corroborates that ovariole activation in 25-day-old virgin queens after mating occurred normally because a large quantity of protein was detected in the oocyte by the mercury bromophenol test and positive PAS granules, probably glycogen, were shown. Another characteristic of the vitellogenesis process is the presence of small granules in the oocyte periphery and later accumulation of granules of various sizes throughout the oocyte (Cruz-Lanim et al., 1971; Cruz-Landim and Caetano, 1981; Fleig, 1995) that was observed in M. q. authidioides queens fertilized up to 25 days of virginity.

Although the ovarioles degeneration advance with age in the M. q. authidioides virgin queen, this degeneration only caused permanent sterility in virgin queens older than 30 days.

\section{Acknowledgements}

The Brazilian research agencies CNPq, CAPES and FAPEMIG supported this research.

\section{References}

Bell, W.J., Bohm, M.K., 1975. Oosorption in insects. Biol. Rev. 50, 373-396. Bownes, M., 1989. The roles of juvenile hormone, ecdysone and the ovary in the control of Drosophila vitellogenesis. J. Insect Physiol. 35, 409-413.

Büning, J., 1994. The Insect Ovary. Ultrastructure, Previtellogenic Growth and Evolution. Chapman \& Hall, London.

Camargo, C.A., 1984. Spermatozoa numbers and migration to the seminal vesicles in haploid and diploid males of Melipona quadrifasciata Lep. J. Agricult. Res. 23, 15-17.

Chapman, R.F., 1998. The Insects: Structure and Function, 4th ed. Cambridge University Press, Cambridge.

Chaud-Netto, J., Stort, A.C., 1980. Successful mating of chatreuse-eyed queens of Apis mellifera (Hymenoptera: Apidae). Ciência Cultura 32, 1542-1543. 
Chen, P.S., Stumm-Xollinger, E., Aigaki, T., Balmer, J., Bienz, M., Bohlen, P., 1988. A male accessory gland peptide that regulates reproductive behavior of female Drosophila melanogaster. Cell 54, 291-298.

Coleman, S., Drähn, B., Petersen, G., Stoloron, J., Draus, K., 1995. A Drosophila male accessory gland protein that us a member of the sepin superfamily of proteinase inhibitors is transferred to female during mating. Insect Mol. Biol. 25, 203-207.

Cruz-Landim, C., Cruz-Höfling, M.A., 1971. Cytochemical ultrastructural studies on eggs from workers and queens of Trigona (Scaptotrigona) postica. Revista Brasileira Pesquisas Médicas Biológicas 4, 19-25.

Cruz-Landim, C., Caetano, F.H., 1981. The histochemistry and fine structure of the vitellarium in Atta (Formicidae, Myrmicinae). Revista Brasileira Biologia 41, 363-370.

Cruz-Landim, C., 2004. Biologia do desenvolvimento das abelhas. IB UNESP/ Rio Claro. http://www.rc.unesp.br/ib/biologia/carminda.html.

Davis, N.T., 1964. Studies of the reproductive physiology of Cimidae (Hemiptera). I. Fecundation and egg maturation. J. Insect Physiol. 10, 947-964.

Engelmann, F., 1970. The Physiology of Insect Reproduction. Pergamon Press, New York.

Fleig, R., 1995. Role of follicle cells for yolk uptake in ovarian follicles of the honey bee Apis mellifera L. (Hymenoptera, Apidae). International. J. Insect Morphol. Embryol. 24, 427-433.

Fill, A., 1978. Follicle cell bridges in the mosquito ovary: Syncytia formation and bridge morphology. J. Cell Sci. 31, 137-143.

Hartfelder, K., Bitondi, M.M.G., Santana, W.C., Simões, Z.L.P., 2002. Ecdysteroid titer and reproduction in queens and workers of the honey bee and of a stingless bee: Loss of ecdysteroid function at increasing levels of sociality? Insect Biochem. Mol. Biol. 32, 211-216.

Hatakoshi, M., 1992. An inhibitory mechanism over oviposition in the tobacco cutworn, Spodoptera litura by juvenile hormone analogue pyriproxyfen. J. Insect Physiol. 38, 793-801.
Huebner, E., 1981. Oocyte-follicle cell interaction during normal oogenesis and atresia in an insect. J. Ultrastruct. Res. 74, 95-104.

Martins, G.F., Serrão, J.E., 2004. Changes in the reproductive tract of Melipona quadrifasciata anthidioides (Hymenoptera, Apidae, Meliponini) queen after mating. Sociobiology 44, 241-254.

Melo, G.A.R., Buschini, M.L.T., Campos, L.A.O., 2001. Ovarian activation in Melipona quadrifasciata anthidioides queens triggered by mating plug stimulation (Hymenoptera, Apidae). Apidologie 32, 355-361.

Neves, C.A., Serrão, J.E., Gitirana, L.B., 2003. Ultrastructural study of the metamorphosis in the midgut of Melipona quadrifasciata anthidioides (Apidae, Meliponini) worker. Sociobiology 41, 443-459.

Patricio, K., Cruz-Landim, C., 2002. Mating influence in the ovary differentiation in adult queens of Apis mellifera L. (Hymenoptera, Apidae). Braz. J. Biol. 62, 641-649.

Pearse, A.G.E., 1985. Histochemistry: Theoretical and Applied. Churchill, London.

Ries, E., 1932. Die prozesse der eibildung und des eiwachstums bei pediculiden und mallophagen. Zeitschrift. Zellforschung Microscopische 16, 314-388.

Snodgrass, R.F., 1935. Principles of Insect Morphology. McGraw-Hill Book, New York

Stefanini, M., Demartino, C., Zamboni, L., 1967. Fixation of ejaculated spermatozoa for electron microscopy. Nature 216, 173-174.

Telfer, W.H., 1965. The mechanism and control of yolk formation. Annu. Rev. Entomol. 10, 161-184.

Watson, J.A.L., 1964. Moulting and reproduction in the adult firebrat Thermobia domestica P. (Thysanura, Lepismatidae). II. The reproductive cycles. J. Insect Physiol. 10, 399-408.

Wheeler, D., 1996. The role of nourishment in oogenesis. Annu. Rev. Entomol. 41, 407-431.

Wolfner, M.F., 1997. Tokens of love, functions and regulation of Drosophila male accessory gland products. Insect Biochem. Mol. Biol. 27, 179-192. 